\title{
Analysis of Correlation Between the Severity of Urinary Incontinence and Sexual Function in Women with Pelvic Floor Dysfunction
}

\author{
Suellen Viana Lucena ${ }^{1, ~ *}$, Daniele Matos de Moura Brasil ${ }^{1}$, Débora Fernandes Britto ${ }^{1}$, \\ Tamires Ferreira do Carmo ${ }^{2}$, Glaucia Nunes Diniz de Oliveira Esmeraldo ${ }^{3}$, \\ Simony Lira do Nascimento ${ }^{3}$, Ana Izabel Oliveira Nicolau ${ }^{4}$, Andreisa Paiva Monteiro Bilhar, \\ Aline Veras Morais Brilhante ${ }^{6}$, Leonardo Robson Pinheiro Sobreira Bezerra ${ }^{1}$ \\ ${ }^{1}$ Department of Surgery, Federal University of Ceará, Fortaleza, Brazil \\ ${ }^{2}$ Faculty of Medicine, Federal University of Ceará, Fortaleza, Brazil \\ ${ }^{3}$ Department of Physical Therapy, Federal University of Ceará, Fortaleza, Brazil \\ ${ }^{4}$ Walter Cantídio University Hospital, Federal University of Ceará, Fortaleza, Brazil \\ ${ }^{5}$ Maternity School Assis Chateubriand, Federal University of Ceará, Fortaleza, Brazil \\ ${ }^{6}$ Faculty of Medicine, University of Fortaleza, Fortaleza, Brazil
}

Email address:

suellenlucena231@yahoo.com (S. V.Lucena)

To cite this article:

Suellen Viana Lucena, Daniele Matos de Moura Brasil, Débora Fernandes Britto, Tamires Ferreira do Carmo, Glaucia Nunes Diniz de Oliveira Esmeraldo, Simony Lira do Nascimento, Ana Izabel Oliveira Nicolau, Andreisa Paiva Monteiro Bilhar, Aline Veras Morais Brilhante, Leonardo Robson Pinheiro Sobreira Bezerra. Analysis of Correlation Between the Severity of Urinary Incontinence and Sexual Function in Women with Pelvic Floor Dysfunction. Journal of Gynecology and Obstetrics. Vol. 6, No. 5, 2018, pp. 108-112. doi: $10.11648 /$ j.jgo.20180605.11

Received: August 10, 2018; Accepted: September 1, 2018; Published: September 25, 2018

\begin{abstract}
Aim The study aimed to analyze the correlation between the intensity of urinary incontinence (UI) in women by the International Consultation on Incontinence Questionnaire-Short Form (ICIQ-SF) and sexual function by the Female Sexual Function Index (FSFI). Methods: Cross-sectional, correlational and quantitative study. It was developed in the urogynecology clinic with 110 women with stress or mixed UI. Exclusion criteria: overactive bladder syndrome, stage of pelvic organ prolapsed $>3$, neurological disease or dementia. The FSFI consists of 19 questions assessing female sexual function in the last 4 weeks in the areas of sexual desire, arousal, vaginal lubrication, orgasm, sexual satisfaction and pain. It was considered final score $\leq 26.5$ indicative of sexual dysfunction. The UI was evaluated using the (ICIQ-SF) consists of 4 items such as frequency of UI, volume, impact of UI on daily life and urinary symptoms. Results: There was a statistically significant relationship between the final ICIQ-SF result $($ mean $=13)$ and the final FSFI score $($ mean $=23.4),(p=0.004)$. The higher the ICIQ-SF final score, the lower the final FSFI score. The FSFI domains most affected by UI severity as evidenced by ICIQ-SF were: sexual desire $(p=0.000)$, sexual arousal $(p=0.036)$ and satisfaction $(p=0.010)$. Conclusions: There was a strong correlation between the severity of stress and mixed UI and sexual function in the studied population. The UI negatively interferes with the woman's desire, arousal, and sexual satisfaction.
\end{abstract}

Keywords: Pelvic Floor Disorders, Urinary Incontinence, Sexual Health, Sexuality, Women's Health

\section{Introduction}

Pelvic floor dysfunction (PFD) is the inability of the pelvic floor to perform its supportive action to the urinary, genital and anorectal organs and/or their functional incapacity of such organs. [1] PFD including urinary incontinence (UI), pelvic organ prolapse (POP), anorectal dysfunctions and sexual dysfunction. [2, 3]

According to a study developed in the United States of America, PFD diseases will increase significantly, and 
around 43.8 million americans will suffer from at least one type of PFD in 2050. [4]

The International Continence Society (ICS) defines UI as involuntary loss of urine. In general, classified as: stress UI (SUI) is involuntary loss of urine associated with stress, urgency UI (UUI) is involuntary loss of urine associated with urgency and mixed UI (MUI) is involuntary loss of urine associated with urgency and stress. [1]

UI affects sexuality, existing partnerships, new partnerships, and the pursuit of professional help. [5] The complaints of urinary symptoms reported by women with UI suggest the need for a proper gynecological examination and evaluation of sexual function. [6,7]

The severity of UI can be assessed by the International Consultation on Incontinence Questionnaire-Short Form (ICIQ-SF) investigating situations of involuntary loss of urine and the impact of UI on quality of life, consisting of 4 items such as frequency of UI, volume, impact of UI on daily life and urinary symptoms. [8]

The female sexual function can be analyzed by the Female Sexual Function Index (FSFI) for sexually active women, with multiple choice questions subdivided into six domains: desire, arousal, lubrication, orgasm, satisfaction and pain. [9]

From this context, the need arises for research that addresses the sexuality of women with UI. The present study aims to analyze the correlation between the severity of UI and the sexual function of women with PFD.

\section{Methods}

\subsection{Type of Study}

This cross-sectional, a descriptive study took place in the Urogynecology and PFD Outpatient, in Fortaleza, in a public institution (Maternity School Assis Chateaubriand) and a private clinic (Pelvic Clinic). Both locals are reference centers, and part of the Brazilian Health System. These services count with interdisciplinary teams formed by physicians, physiotherapists and nurses.

\subsection{Patients}

We studied 114 women with SUI or MUI, the age ranged from 30 to 79 years, whose diagnosis of the type of UI was based on the clinical complaints presented followed by Urodynamic testing, from September 2016 to July 2017.

The following were excluded from the study: women diagnosed with overactive bladder syndrome (OAB), POP of stage $>3$, objectively evaluated by Urogynecology measured by the Pelvic Organ Prolapse Quantification (POP-Q) [10], neurological disease, dementia, presenting some disease related to articulation of speech or hearing that prevented responding to questionnaires and refusal to participate in the research. Twenty-six women were excluded by the cited criteria, with a sample of 88 women, which 51 were sexually active women who were able to evaluate the sexual function by FSFI.

As for the sample calculation, according to the statistical program $\mathrm{G} *$ Power 3.1.9.2, the maximum sampling error was $15 \%$ for estimating the impact of UI on female sexual function, in order to show the power of the sample of $80 \%$ and the $95 \%$ confidence level, according to established statistical standards for quantitative research. [11]

\subsection{Data Collect}

Data collection took place during an Urodynamic testing. To collect data on socioeconomic status, and for division of social classes, we used the criteria the Questionnaire for Economic Status Classification 2014(CCEB 2014) of ABEP (Brazilian Association of Research Companies). According to CCEB, the education of the head of the family is worth from 0 to 5 points; the other points are provided by the amount of durable consumer goods that the family owns, due to the number of rooms in the house, toilets, and by the amount of domestic monthly employees who work in the house. The sum of these indicators corroborates the distribution of the population in classes, with class A1 being 45 to 100 points the most privileged and Class D and E from 0 to 16 points, the least privileged. [12]

In order to assess the severity of the UI, the ICIQ-SF was used: a simple, brief questionnaire to quickly assess the impact of UI on quality of life and to qualify the urinary loss of patients from both the sexes. It was originally developed and validated in the English language. [8]

The FSFI questionnaire assesses female sexual function. This validated questionnaire for Portuguese is composed of multiple choice questions, each response takes values from 0 to 5 , so the results range from 2 to 36 , and the lower the score obtained, the worse the sexual function. The questionnaire scores conceptualize as sexual dysfunction when the total score is less than 26.5. [9, 13, 14] Data collection participants received training by a health professional specialized in human sexuality for the use of such questionnaire.

\subsection{Ethical Aspects}

This study followed the norms presented in Resolution 466/12 of the National Health Council of Brazil of the Ministry of Health for conducting research with human beings. We emphasize that the following data were collected after the patient signed a standard Consent Form for voluntary participation in the study. [15] This research was authorized by the Committee of Ethics in Research of Maternity School Assis Chateaubriand, under number 1.739.920.

\subsection{Data Analysis}

Statistical analysis was made using the SPSS for Windows, release 20.0 (SPSS Inc., Chicago, IL, USA) and Progam R 3.3.1: The $\mathrm{R}$ Project for Statistical Computing. The Kolmogorov-Smirnov test was used to verify if the quantitative data were distributed according to normal standards. To verify the correlation between ICIQ-SF and FSFI, quantitative data, we used the Spearman test. A p value $<0.05$ was considered statistically significant. 


\section{Results}

Among the participants of the study, the power of the sample of $80 \%$, the age ranged from 30 to 79 years, with a mean of 52.5 years. The majority of women $(71.6 \%)$ were in the age group between 40 and 64 years. A percentage of the participants $(45.4 \%)$ had low level of education, evidenced by the non-completion of secondary education. As for the marital status, $69.3 \%$ of the women were married or lived in a stable union. Concerning CCEB, class C (38.6\%) was the most predominant. About $56.8 \%$ of the female population does not perform work and $68 \%$ were attended at a public health institution (Table 1).

Table 1. Distribution of sociodemographic characteristics of women with UI. Fortaleza, Ceará, November, 2017.

\begin{tabular}{lll}
\hline Sociodemographic characterization & $\mathbf{n}(\%)$ & Mean \pm SD \\
\hline Age group $(\mathrm{n}=88)$ & & \\
$30-39$ & $9(10.2)$ & $52.5 \pm 11.3$ \\
$40-64$ & $63(71.6)$ & Min: 30 \\
$\geq 65$ & $16(18.2)$ & Max: 79 \\
Educational level(n=88) & & \\
Illiterate & $14(15.9)$ & \\
Basic education & $26(29.5)$ & \\
High school & $34(38.6)$ & \\
\hline
\end{tabular}

\begin{tabular}{lll}
\hline Sociodemographic characterization & $\mathbf{n}(\%)$ & Mean \pm SD \\
\hline Higher education & $14(15.9)$ \\
Marital status(n=88) & \\
Single & $16(18.2)$ \\
Married & $61(69.3)$ \\
Divorced & $8(9.1)$ \\
Widow & $3(3.4)$ \\
Social Class $(\mathrm{n}=88)$ & \\
A & $7(8)$ \\
B & $23(26.1)$ \\
C & $34(38.6)$ \\
DE & $24(27.3)$ \\
Occupation $(\mathrm{n}=88)$ & \\
No & $53(60.2)$ \\
Yes & $35(39.7)$ \\
Health service $(\mathrm{n}=88)$ & \\
Public & $60(68)$ \\
Private & $28(31.8)$ \\
\hline
\end{tabular}

Search data (2018)

Regarding the correlation of ICIQ-SF and FSFI, it can be said that they are inversely proportional. The higher the ICIQ score, the more severe the UI and the greater the negative effect on sexual function, with lower FSFI scores.

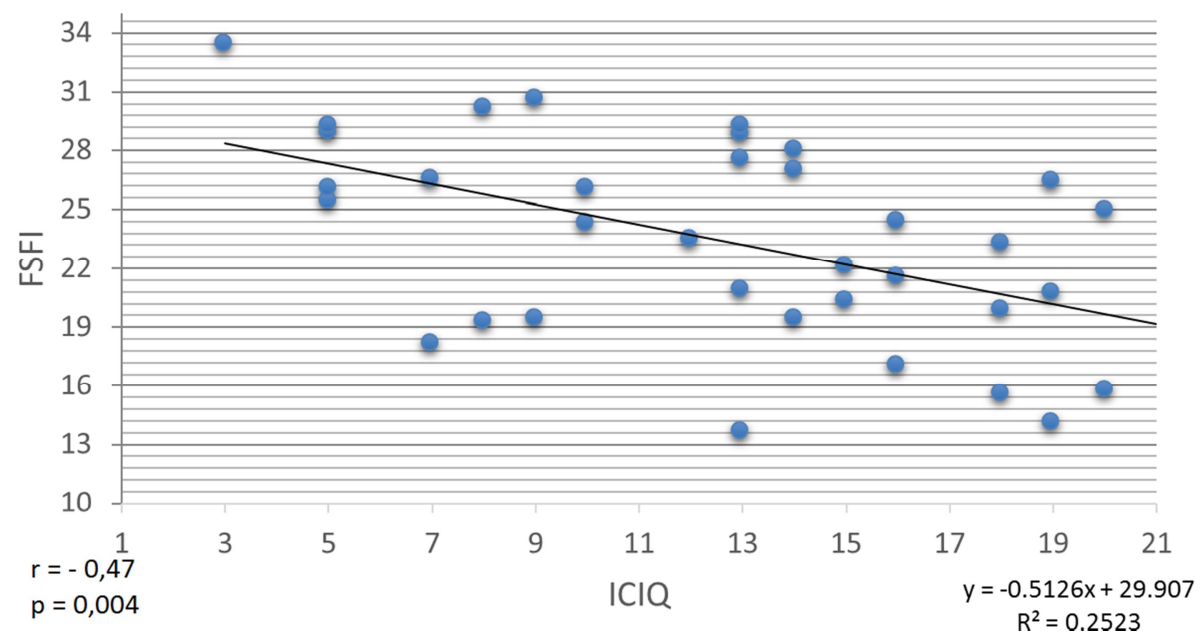

Figure 1. Relationship of female sexual function versus the severity of urinary incontinence. Search data (2018).

The domains of FSFI that are most affected by the greater severity of UI seen by ICIQ are desire, arousal and sexual satisfaction (Table 2).

Table 2. Correlation between the severity of UI (ICIQ-SF) and domains of female sexual function (FSFI).

Fortaleza, Ceará, November, 2017.

\begin{tabular}{lllllll}
\hline ICIQ -SF & Desire & Arousal & Lubrication & Orgasm & Satisfaction & Discomfort-pain \\
\hline Spearman's Spear & -0.584 & -0.355 & -0.135 & -0.315 & -0.429 \\
$\mathrm{p}$ & $<0.01 *$ & $0.03 *$ & $0.43 *$ & $0.06^{*}$ & 0.163 & $0.01 *$ \\
\hline
\end{tabular}

* Spearman test. Search data (2018)

\section{Discussion}

A survey conducted in Taiwan with 4,661 women between the ages of 35 and 64 showed that the prevalence of UI among participants aged 35-44 years (14.7\%), 45-54 years
$(24.7 \%)$ and 55- 64 years old (32.4\%). Identified as risk factors for UI: higher age, higher parity, higher BMI (body mass index), hormone replacement therapy (HRT) returns, have a psychiatric illness, hyperlipidemia and respiratory diseases. The negative effects on UI quality of life and sexual life are greater when compared to other chronic diseases. [16] 
The present study showed the profile of women with UI predominantly inserted in the age group 40 to 64 years old, with low level of schooling, married or living in a stable union, without work activity similar to the another research [17] on the prevalence of UI, in an exploratory study in Piauí, state of northeast of Brazil. It is necessary to identify the profile of female UI in order to investigate the possible associated socioeconomic factors.

It was observed that the more severe the UI, the greater the negative effect on sexual function. This findings are compatible with studies [18] who observed that women with UI had a higher prevalence of sexual abstinence, less sexual desire, foreplay, partner harmony, comfort and sexual satisfaction, as well as, women with greater urinary loss had the worst sexual performance. In one study [19] to found a weak correlation between FSFI sexual function and ICIQ-SF UI severity in a cross-sectional study with 113 postmenopausal women.

Women with UI in a case-control study in Malaysia had lower overall sexual function, lower frequency of sexual intercourse, lower satisfaction $(\mathrm{p}<0.001)$, and higher sex deprivation behavior $(\mathrm{P}=.026)$. [20] On the other hand, in a study of 1217 women in Turkey, UI negatively affected sexual function, but there was no correlation between the FSFI total score and the ICIQ-SF score. [21]

A US study of 505 women found that activity rates and sexual function are not different among women with and without PFD. Sexually active women were classified as having moderate UI and those who were sexually inactive had more severe UI complaints. [22]

In most studies, women with UI have reported associated sexual dysfunction, being an important condition that should be investigated in this group of patients, so that the woman is treated in a more complete way.

\section{Conclusion}

In conclusion, the study revealed a strong correlation between stress severity and mixed UI and sexual function in the studied population. The more serious the UI, the worse the female sexual function. The UI negatively interferes with the desire, arousal and sexual satisfaction of the woman, which affects the quality of sexual life. This suggests the need for interventions as a form of strategies to promote the sexual health of the female population.

\section{Acknowledgements}

The Foundation Cearense of Support to the Scientific and Technological Development (FUNCAP) for the financial support granted for the accomplishment of the research sob Process of $n^{\circ}$ BMD-0008-00920.01.06/16.

\section{Conflict of Interest}

No conflict of interest statement for each author.

\section{References}

[1] Haylen BT, Ridder D, Freeman RM, et al. An International Urogynecology Association (IUGA) / International Continence Society (ICS) joint report on the terminology for female pelvic floor dysfunction. International Urogynecology Journal. Vol.21, No.1, 2010, pp.5-26. doi: 10.1007/s00192-009-0976-9.

[2] Bump RC, Norton PA. Epidemiology and natural history of pelvic floor dysfunction. Obstetrics Gynecology Clinics of North America. Vol.25, No.4, 1998, pp.723-746.

[3] Almeida MBA, Barra AA, Figueiredo EM, et al. Disfunções de assoalho pélvico em atletas. Femina. Vol.39, No.8, 2011, pp. 395-402.

[4] Wu JM, Hundley AF, Fulton RG, Myers ER. Forecasting the Prevalence of Pelvic Floor Disorders in U.S. Women 2010 to 2050. American College of Obstetricians and Gynecologists. Vol. 114, No. 6, 2009, pp. 1278-1283.

[5] Hayder D. The effects of urinary incontinence on sexuality: seeking an intimate partnership. Journal of Wound Ostomy \& Continence Nursing. Vol.39, No.5, 2012, pp. 539-544.

[6] Frank JE, Mistretta P, Will J. Diagnosis and treatment of female sexual dysfunction. American Family Physician. Vol.77, No. 5, 2008, pp.635-642.

[7] Cardoso J. Sexualidade na doença crónica e na defíciência física. Revista Portuguesa de Medicina Geral e Familiar. Vol. 20, No. 3, 2004, pp. 385-94.

[8] Tamanini JTN, Dambros M, D'ancona CAL, Palma PCR, Netto Jr. NR. Validation of the "International Consultation on Incontinence Questionnaire - Short Form" (ICIQ-SF) for Portuguese. Revista de Saúde Pública. Vol.38, No. 3, 2004, pp.438-444. doi: 10.1590/S0034-89102004000300015.

[9] Thiel RRC, Dambros M, Palma PCR, Thiel M, Riccetto CLZ, Ramos MF. Tradução para português, adaptação cultural e validação do Female Sexual Function Index. Revista Brasileira de Ginecologia e Obstetrícia. Vol.30, No.10, 2008, pp.504-510. doi: 10.1590/S0100-72032008001000005.

[10] Abrams P, Cardozo L, Fall M, et al. The standardisation of terminology of lower urinary tract function: report from the standardisation sub-committee of the international continence society. Neurourology and Urodynamics. Vol.21, No.2, 2002, pp.167-178.

[11] Faul F et al. G* Power 3: A flexible statistical power analysis program for the social, behavioral, and biomedical sciences. Behavior research methods. Vol. 39, No. 2, 2007, pp. 175-191.

[12] Brazilian Association of Research Companies (ABEP). Economic Classification Criteria Brazil. http://www.abep.org/criterio-brasil. Available 2014. Access April 17, 2016.

[13] Pacagnella RC, Martinez EZ, Vieira EM. Validade de construto de uma versão em português do Female Sexual Function Index. Caderno de Saúde Pública. Vol. 25, No. 11, 2009, pp. 2333-2344.

[14] Wiegel M, Meston C, Rosen R. The female sexual function index (FSFI): cross-validation and development of clinical cutoff scores. Journal of Sex \&Marital Therapy. Vol. 31, No. 1, 2005, pp. 1-20. 
[15] Ministry of Health (BR). National Health Council. National Commission on Health Ethics. CNS Resolution 466/12. Norms for research involving human beings. Official Journal of the Union, Executive Branch, Brasília, DF, 2012.

[16] Horng SS, Huang N, Wu SI, Fang YT, Chou YJ, Chou P. The Epidemiology of Urinary Incontinence and it's Influence on Quality of Life in Taiwanese Middle-Aged Women. Neurourology and Urodynamics. Vol. 32, No. 4, 2013, pp. 371-376.

[17] Mourão LF, Luz MHBA, Marques ADB, Benício CDAV, Nunes BMVT, Pereira AFM. Caracterização e fatores de risco de incontinência urinária em mulheres atendidas em uma clínica ginecológica. Estima. Vol. 15, No. 2, 2017, pp. 82-91.

[18] Felippe MR, Zambon JP, Girotti ME, et al. What Is the Real Impact of Urinary Incontinence on Female Sexual Dysfunction? A Case Control Study. The Journal of Sexual Medicine. Vol. 5, No. 1, 2017, pp. 54-60. doi: 10.1016/j.esxm.2016.09.001.
[19] de Menezes Franco M, Driusso P, BøK et al. Relationship between pelvic floor muscle strength and sexual dysfunction in postmenopausal women: a cross-sectional study. Internacional Urogynecology Journal. Vol. 28, No. 6, 2017, pp. 931-936.

[20] Lim R, Liong ML, Leong WS, Khan NAK, Yuen KH. Effect of stress urinary incontinence on the sexual function of couples and the quality of life of patients. Journal of Urology. Vol. 196, No. 1, 2016, pp. 153-158. doi: 10.1016/j.juro.2016.01.090.

[21] Çayan S, Yaman O, Orhan I, et al. Prevalence of sexual dysfunction and urinary incontinence and associated risk factors in Turkish women. European Journal of Obstetrics \& Gynecology Reproductive Biology. Vol.203, 2016, pp.303-308. doi:10.1016/j.ejogrb.2016.06.030.

[22] Fashokun, TBO, Harvie HS, Schimpf MO, Et al. Sexual activity and function in women with and without pelvic floor disorders. Internacional Urogynecology Journal, Vol.24, No.1, 2013, pp. 91-97. 